\title{
When do households invest in solar photovoltaics? An application of prospect theory
}

This is a self-archived, non-commercial personal copy of an accepted manuscript published in Energy Policy available at http://dx.doi.org/10.1016/j.enpol.2017.06.067.

(c) 2017. This manuscript version is made available under the CC-BY-NC-ND 4.0 license http://creativecommons.org/licenses/by-nc-nd/4.0/.

Please cite as:

Klein, M. \& Deissenroth, M., 2017. When do households invest in solar photovoltaics? An application of prospect theory. Energy Policy, 109, pp.270278, DOI: 10.1016/j.enpol.2017.06.067. 


\title{
When Do Households Invest in Solar Photovoltaics? An Application of Prospect Theory
}

\author{
Martin Klein*, Marc Deissenroth \\ German Aerospace Center (DLR), Institute of Engineering Thermodynamics, Department \\ Systems Analysis and Technology Assessment, Pfaffenwaldring 38-40, 70569 Stuttgart, \\ Germany
}

\begin{abstract}
While investments in renewable energy sources (RES) are incentivized around the world, the policy tools that do so are still poorly understood, leading to costly misadjustments in many cases. As a case study, the deployment dynamics of residential solar photovoltaics (PV) invoked by the German feed-in tariff legislation are investigated. Here we report a model showing that the question of when people invest in residential PV systems is found to be not only determined by profitability, but also by profitability's change compared to the status quo. This finding is interpreted in the light of loss aversion, a concept developed in Kahneman and Tversky's Prospect Theory. The model is able to reproduce most of the dynamics of the uptake with only a few financial and behavioral assumptions.
\end{abstract}

Keywords: Deployment Modeling, Investment, Feed-in Tariff Design, Photovoltaics, Prospect Theory

\footnotetext{
* Corresponding author

Email address: m.klein@dlr.de (Martin Klein)
} 


\title{
When Do Households Invest in Solar Photovoltaics? An Application of Prospect Theory
}

\begin{abstract}
While investments in renewable energy sources (RES) are incentivized around the world, the policy tools that do so are still poorly understood, leading to costly misadjustments in many cases. As a case study, the deployment dynamics of residential solar photovoltaics (PV) invoked by the German feed-in tariff legislation are investigated. Here we report a model showing that the question of when people invest in residential PV systems is found to be not only determined by profitability, but also by profitability's change compared to the status quo. This finding is interpreted in the light of loss aversion, a concept developed in Kahneman and Tversky's Prospect Theory. The model is able to reproduce most of the dynamics of the uptake with only a few financial and behavioral assumptions.
\end{abstract}

Keywords: Deployment Modeling, Investment, Feed-in Tariff Design, Photovoltaics, Prospect Theory

\section{Introduction}

The majority of countries has RES targets and support policies in place (REN21, 2016). Such deployment policies, i.e. the desired diffusion of RES into the market via remunerations like feed-in tariffs, tenders or market premiums, can be effective tools in creating a market pull which fosters the uptake of renewables and can, if well designed, invoke technological evolution and innovation (Hoppmann et al., 2013). There is little insight, however, on how to set adequate remuneration levels and when to adjust them, mainly because the drivers and dynamics of investment are poorly quantified. The policy instruments that try to incentivize RES deployment therefore often fail to reach desired quantities. Costly misadjustments could be avoided with a better understanding of deployment and diffusion dynamics.

The modeling of market diffusion of RES and in particular photovoltaics (PV) has attracted a considerable amount of research interest in recent years. While there is a fairly large body of literature on how to set optimal levels of remunerations via real option analysis (for an overview see e.g. Zhang et al. (2016)), or how firms would ideally time and size investments under regulatory uncertainty (see e.g. Chronopoulos et al. (2016)), a growing body of research shows that the residential sector behaves rather differently. For instance, the 
intention formation of home-owners to adopt PV does not solely depend on optimality principles and financial factors (see e.g. (Korcaj et al. 2015)). Energy policy can benefit from a more detailed consideration of behavior (Allcott and Mullainathan, 2010). However, methods that take into account more realistic or boundedly rational decision rules have had little impact on the evaluation of residential deployment dynamics - modeling of small scale investments in RES is challenging since many heterogeneous actors and motives are involved.

So far, scholars have focused on the socio-demographics of home-owners and the evaluation of local peer effects (see e.g. (Bollinger and Gillingham, 2012 Kwan, 2012, Rode and Weber, 2016)). They find that localized peer-topeer communications reduce barriers to PV adoption (Rai and Robinson, 2013). Most recently, elaborate agent-based modeling approaches have been presented by Palmer et al. (2015) and Rai and Robinson (2015), which combine both socio-economic characteristics and peer effects. While all of these approaches provide a detailed view of the drivers and boundaries of RES uptake, these evaluations are relatively hard to trace back and generalize, as they require granular spatial socio-economic data in the former and relatively specific agent specification in the latter case. They are therefore hard to apply to other cases and not reducible to analytic demand formulas and hence of limited use if to be applied in a whole systems energy modeling context.

Curve fitting approaches try to fill this gap and relate the economic profitability of a representative PV project with observed aggregated deployment rates. Grau (2014) mapped the profitability of PV onto the deployment observed in Germany via a logarithmic fit function. A dynamic time lag between investment decision and installation is proposed, which is reduced in situations when remuneration reductions are announced. Similar exponential curve fitting contributions have been made by van Benthem et al. (2008) and Wand and Leuthold (2011), additionally with technology diffusion terms. Similarly, Lobel and Perakis (2011) are applying a logit demand function, where the utility of adoption mainly depends on profitability and the logarithm of cumulative installations. All of these approaches, however, provide only limited insight into the dynamics of observed deployment rates, as they either only focus on yearly installation values van Benthem et al., 2008, Lobel and Perakis, 2011, Wand and Leuthold, 2011) or must be recalibrated over time to make up for unknown dynamic changes in the adoption behavior (Grau, 2014). Finally, Leepa and Unfried (2013) present a time-series analysis of the effect of remuneration cuts on the investment behavior of PV in Germany and find that step-wise adjustments temporarily accelerate installments. However, a limit of their study is that they cannot establish causal relationships.

To summarize, a need for dynamic, fundamental, parsimonious models which are able to depict the magnitude of PV deployment over time is identified. The aim of this study is to address this research gap.

The remainder is structured as follows: Section 2 introduces the research case - residential PV deployment in Germany over the years of 2006-2014 - and explains why this is a useful example to study deployment dynamics and the interaction with the policy regime. Section 3 is concerned with the methodology, 
i.e. the techno-economic modeling of PV systems. A way to calculate mean internal rates of return via a Monte Carlo simulation method is presented. The deployment modeling via utilities, and most notably, our proposed extension with the value function of prospect theory, is presented. Section 4 presents a deployment analysis on absolute level of PV profitability, and most notably, shows how this approach fails to capture the subyearly investment dynamics. The evaluation then presents how prospect theory can be used to explain the stylized features of the subyearly deployment dynamics substantially better. Section 5 discusses the findings, and points out to possible shortcomings and extensions of the study. Section 6 concludes with policy recommendations.

\section{Research Case - Residential Photovoltaics in Germany}

To study the market diffusion of RES, the case of residential PV deployment in Germany over the years of 2006-2014 is investigated. As one of the earliest examples of a RES incentive program, the German government introduced the Renewable Energy Sources Act (EEG) in 2000. Among others things, the act regulates the remuneration of RES, which are granted a technology-specific compensation for each kWh of electricity fed into the grid. For photovoltaics, the instrument has been effective in creating a dynamic demand and a competitive supplier and installation industry (Seel et al., 2014).

This feed-in tariff remuneration scheme is a remarkable possibility to study the impacts of incentives on the observed deployment dynamics: The basic logic of the incentive program - a fixed compensation for 20 years starting with the date of initial operation - did not change for residential PV; the level of remuneration and system costs, however, have changed. This allows to examine the effect of this particular policy instrument by assessing the relationship between profitability of PV systems and the aggregated deployment.

Remuneration adjustments were necessary because the economics of PV have been shifting rapidly (Candelise et al. 2013): PV module cost decreased by approximately $80 \%$ in the last 10 years alone (Farmer and Lafond, 2016). Figure 1 depicts the relative development of PV module cost and feed-in tariffs for solar photovoltaic systems. These developments were not in alignment at all times, especially in the year 2009-2012. As module prices fell, remunerations were decreased, often hastily, between 2006-2010 stepwise in a yearly way, between 2010-2012 in higher iterations as the rapid price decline made more amendments necessary, and since April 2012 on a monthly basis in dependence of the actual deployment over the past year.

Figure 2 illustrates the monthly PV installations $<10 \mathrm{~kW}_{\mathrm{p}}{ }^{1}$ between 2006 and 2014, in total about 700,000 installations. The development is characterized

\footnotetext{
${ }^{1} \mathrm{~kW}_{\mathrm{p}}$ is an often employed unit to depict the nominal power of PV systems. It measures the output of a system under peak (hence the "p") conditions, i.e. standard testing conditions with a horizontal irradiance of $1 \mathrm{~kW} / \mathrm{m}^{2}$ at $25^{\circ} \mathrm{C}$ ambient temperature.
} 


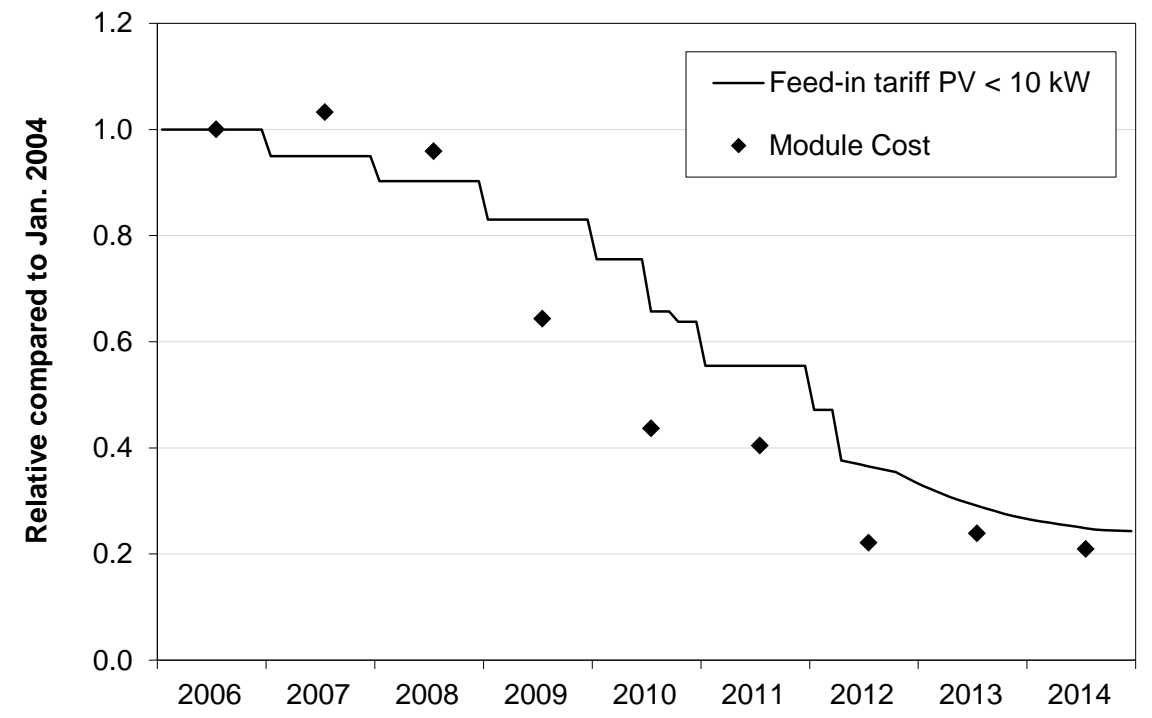

Figure 1: Relative development of feed-in tariff and PV module costs. The feed-in tariff for residential PV systems with a capacity of $<10 \mathrm{~kW}_{\mathrm{p}}$ is shown by the solid line. The markers indicate the PV module costs in the same period of time. Both feed-in tariff and module cost developments are given relative to their values in January 2006. The sharp decrease in PV module cost made tariff adjustments necessary, and the developments were not in alignment at all times. Data source: (Bundesnetzagentur, 2016 Farmer and Lafond, 2016) 


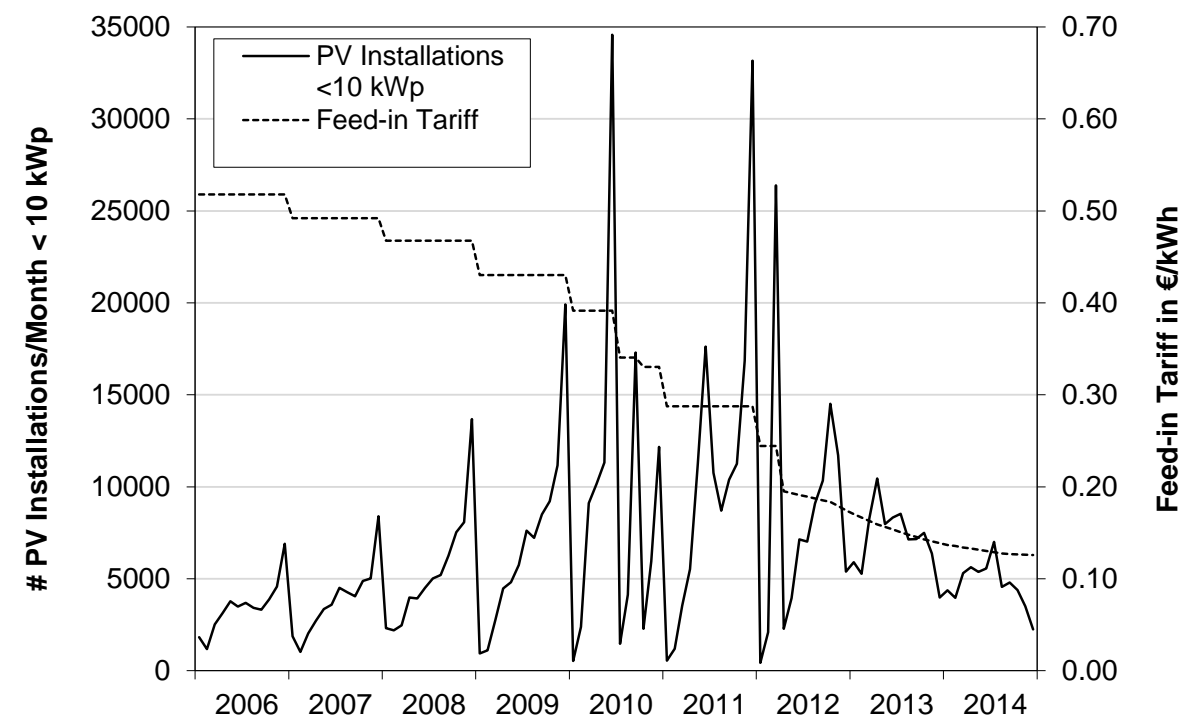

Figure 2: Monthly PV installations and feed-in tariff. For the years 2006 to 2014, the installations of PV systems $<10 \mathrm{~kW}_{\mathrm{p}}$ per month are depicted by the solid line, corresponding numbers are given on the left axis. The dashed line shows values of the feed-in tariff given in Euro/kWh, scale on the right axis. The installation peaks correspond with anticipated feed-in tariff cuts. Data source: (Bundesnetzagentur 2016, Open Power System Data, 2017)

by pronounced spikes, which correspond with anticipated step-wise feed-in tariff cuts (Leepa and Unfried, 2013).

\section{Methodology}

In order to reduce complexity, the study abstains from looking on individual level decision making and focuses on the aggregate of investment dynamics. To establish a link between the profitability and deployment, home-owners are regarded to consider the installation of a PV system as an investment. As such, PV systems have to compete with other investment possibilities. With decreasing economy wide average rates of return, a lower internal rate of return (IRR) on PV installations becomes more acceptable for profit-oriented installers, as comparative investments on other markets get less attractive. The modeling steps are outlined below and substantiated in the following subsections:

1. Regard residential PV installations as investments, and calculate retrospective net present values (NPVs) per time.

2. Derive a mean IRR in order to compare it to public-sector bond rates.

3. Compile a utility function $u(t)$ that increases exponentially with increasing risk-adjusted IRR. Correlate this utility measure against the deployment curve to see how well the model performs. 
4. As an extension, consider changes in the utility function via the value function of Prospect Theory.

\subsection{Profitability modeling via NPV calculations}

Concerning investment choices, the net present value (NPV) method is often used to decide whether to accept $(\mathrm{NPV}>0)$ and reject $(\mathrm{NPV}<0)$ a project (Brealey and Myers, 2000). This method is used to assess the profitability of PV systems over time. The NPV is calculated as follows:

$$
N P V(r, t)=-C_{0}(t)+\sum_{n=1}^{T} \frac{C_{+, n}(t)-C_{-, n}(t)}{(1+r)^{n}}
$$

where $C_{0}, C_{+, n}, C_{-, n}$ denote initial investment and positive and negative cash flows, respectively, in the $n^{\text {th }}$ year after deployment at time $t . r$ is the discount rate, $T$ the project lifetime. In this case, the initial investment is given by

$$
C_{0}(t)=s \cdot I(s, t)
$$

where $s$ denotes the system size in $\mathrm{kW}_{\mathrm{p}}$ and $I$ the specific investment cost per $\mathrm{kW}_{\mathrm{p}}$. To account for higher specific installation cost for smaller installations, initial investment cost is scaled to the system size $s$ according to:

$$
I(s, t)=I_{0}(t)\left(\frac{s}{10 \mathrm{~kW}_{p}}\right)^{-0.063}
$$

The scaling parameter is derived from Feldman et al. (2012), who provide installation cost data by system size for installations in the year 2011 in the United States. $I_{0}(t)$ is the specific investment cost for installations with a size of $10 \mathrm{~kW}_{\mathrm{p}}$. Positive cash flows $C_{+, n}$ stem from feed-in tariff revenues and avoided cost for grid electricity if part of the generated electricity is self-consumed:

$C_{+, n}(t)= \begin{cases}E_{n} \cdot f(t) & \text { if } f(t)>e(t)+f_{S C}(t) \\ E_{n}\left(f(t) \cdot(1-S C)+\left(e(t)+f_{S C}(t)\right) \cdot S C\right) & \text { else }\end{cases}$

$E_{n}$ is the energy output of the system in year $n, f(t)$ the feed-in tariff at installation time $t$ and $e(t)$ the retail electricity price. Between January 2009 and March 2012, roof-top PV systems could receive an additional feed-in tariff for self-consumed electricity $f_{S C}(t)$, which makes the case differentiation in formula 4 necessary. $S C$ is the self-consumption ratio ${ }^{2}$ The energy output $E_{n}$ of the system in year $n$ is calculated as

\footnotetext{
${ }^{2}$ Defined in Luthander et al. $(2016)$ as "(...) the share of self-consumed electricity relative to total PV electricity production.". Note that the second case in formula 4 is also true if there is no feed-in tariff for self-consumed electricity, but the standard feed-in tariff is lower than the retail electricity price.
} 


$$
E_{n}=s \cdot \gamma \cdot P R \cdot H_{o p t} \cdot(1-d)^{n}
$$

$P R$ denotes the performance ratio of the system, $H_{o p t}$ the irradiance of an optimally inclined surface per $\mathrm{m}^{2}$ and year in $\mathrm{kWh}^{3}$ and $d$ the degradation rate. The factor $\gamma$ can take values from 0 to 1 and describes the roof's deviation from the optimal inclination (with 1 being optimally inclined). For negative cash flows $C_{-, n}$, only operation and maintenance costs are considered and approximated with a yearly fixed share $c_{O \& M}$ of the initial investment:

$$
C_{-, n}=C_{0}(t) \cdot c_{O \& M}
$$

\subsection{Derivation of mean IRR - Monte Carlo Simulation}

Via a Monte Carlo method, the input parameters for the NPV calculation are systematically varied. The method is described in detail by Darling et al. (2011) for PV applications. In difference to most other NPV Monte Carlo simulations, which are used for sensitivity analysis and risk assessment (Hacura et al., 2001), the study uses a slightly different interpretation by generating a set of possible systems which could be implemented in reality. With each Monte Carlo iteration, a single NPV as described in formulas 16 with a randomly drawn set of input parameters is calculated.

Given this input, an economic potential with respect to the discount rate is derived. Here, the economic potential $\Theta$ is defined as the share of acceptable possible projects (NPV $>0$ ) as a function of the discount rate $r$ and deployment time $t$ :

$$
\Theta(r, t)=N^{-1} \sum_{i=1}^{N} \delta_{i}(r, t), \delta_{i}(r, t)= \begin{cases}1 & \text { if } \mathrm{NPV}>0 \\ 0 & \text { if } \mathrm{NPV} \leq 0\end{cases}
$$

where index $i$ denotes a single Monte-Carlo sample and $N$ the total amount of samples (100,000 in our study).

By calculating $\Theta(r, t)$, i.e. the positive share of NPVs, for different discount rates $r$ (in this study from $-10.0 \%$ to $+15.0 \%$ with a step size of $0.5 \%$ ), the mean internal rates of return (IRR) can be identified: The IRR is defined by the rate $r$ for which the NPV is exactly 0 . As can be seen in formula 1. NPV decreases with increasing $r$ (the denominator of the function gets larger) if the cash-flows in the sum are positive, which is the case as the operation and maintenance costs $C_{-, n}(t)$ are relatively small. Hence $\Theta(r, t)$ decreases monotonically if the discount rate $r$ is increased. Some particular possible installations will change sign of NPV from positive to negative with each increasing discount rate step. The retrieved rate $r$ is the particular IRR for those installations.

\footnotetext{
${ }^{3}$ Since the rated capacity in $\mathrm{kW}_{\mathrm{p}}$ is defined as the output under standard testing conditions $\left(1 \mathrm{~kW} / \mathrm{m}^{2}\right)$, the irradiance in $\frac{\mathrm{kWh}}{\mathrm{m}^{2} \mathrm{a}}$ can also be expressed in $\frac{\mathrm{kWh}}{\mathrm{kW}_{\mathrm{p} a}}$, so the units add up.
} 


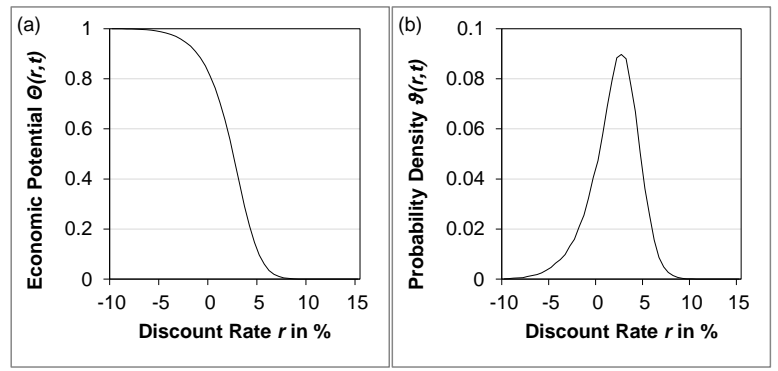

Figure 3: Example for the Economic Potential $\Theta(r, t)$, i.e. the share of positive NPVs, and its derivative, the Probability Density Function of IRRs $\vartheta(r, t)$ for $\mathrm{t}=$ Dec. 2008 .

Hence, the derivative of $\Theta(r, t)$ with respect to $r, \vartheta(r, t)=-\frac{\partial \Theta(r, t)}{\partial r}$, yields the probability density function of IRRs for all projects considered in the simulation, see figure 3 for a graphical representation. It can be interpreted by the slope of the economic potential (Hillier, 1963). The mean IRR value can then be easily extracted from the density function $\vartheta(r, t)$ :

$$
\overline{I R R}(t)=\int r \cdot \vartheta(r, t) d r
$$

In this study, the continuous case was not considered but approximated with a stepwise integration for finite increments of $\Delta r$ :

$$
\overline{\operatorname{IRR}}(t)=\sum_{r} r(\Theta(r, t)-\Theta(r+\Delta r, t))
$$

The derivation of an economic potential via a Monte Carlo simulation of a broad set of possible systems ensures that the economic assessment is as unbiased as possible. Calculating only a single reference system with fixed parameters like irradiation and size could skew the profitability analysis, since the inputs can potentially have non-linear effects on profitability over time. The relative economic prospect of a single PV system could shift from more to less favorably or vice versa (it could be, for instance, that small PV systems are relatively better off in earlier moments of the analysis). Calculating a mean IRR in the way presented can lessen this problem, as a broad share of possible $\mathrm{PV}$ systems is considered.

\subsection{Deployment modeling via a utility function}

The objective of the following two sub-sections is to find some utility measure that correlates well with the observed deployment of residential PV systems. 


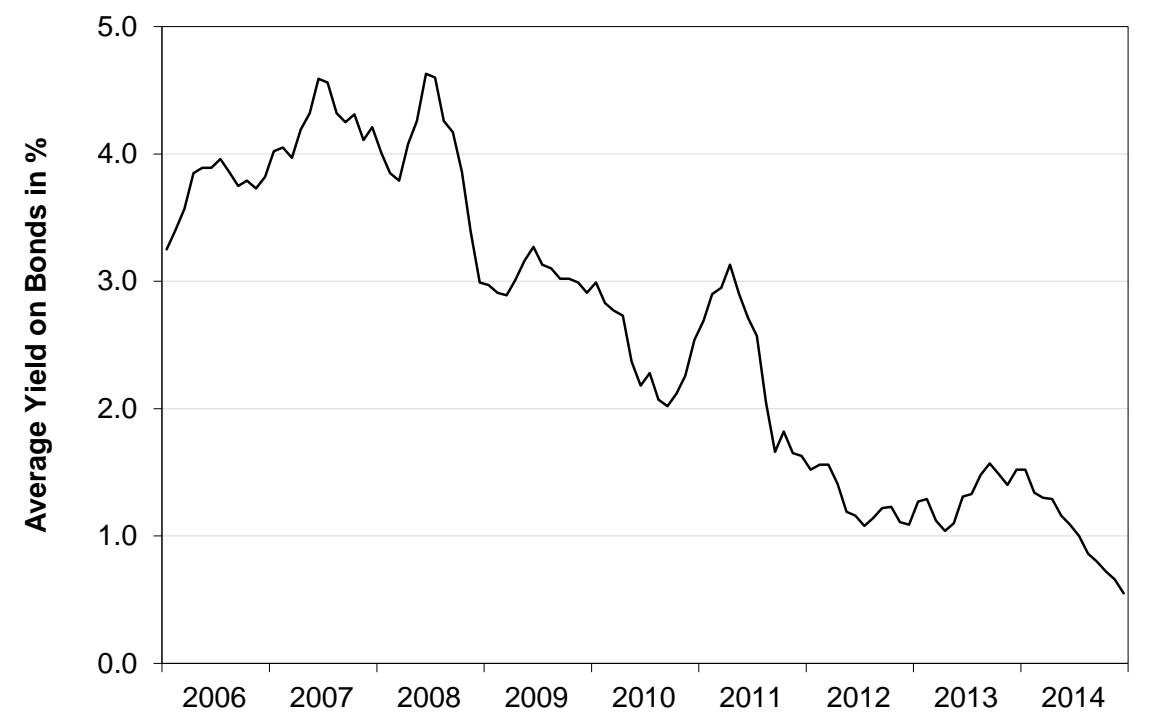

Figure 4: Risk-free rate of return in Germany over time, which is derived from the average yield of public-sector bonds. Data source: Deutsche Bundesbank (2016)

PV system are regarded as an investment that has to compete with economy wide average rates of return. The rate of public-sector bonds has changed considerably: The average return on German government bonds, which is considered to be the risk-free alternative investment for the purpose of our evaluation (abbreviated as $\rho(t)$ ), have been decreasing from nearly 4-5\% in the year 20062008 to less than $1 \%$ in the year 2014 in the aftermath of the financial crisis of 2007-08 and the turmoil on European markets. Figure 4 shows the average yield of public-sector bonds in Germany over time.

The risk-adjusted IRR $\pi(t)$ shall be defined as

$$
\pi(t)=\overline{I R R}(t)-\rho(t)
$$

In the case of continuous interest compounding, the payout $P$ after time $t$ subject to a return rate $r$ can be expressed as an exponential function Brealey and Myers, 2000):

$$
P \propto e^{r t}
$$

Hence, and similar to the fit functions used by van Benthem et al. (2008) and Wand and Leuthold (2011), it is assumed that consumers get an exponentially increasing utility $u(t)$ with an increasing rate of the risk-adjusted IRR $\pi(t)$ (the return rate $r$ in formula 11) if they choose to invest at time $t$ :

$$
u(t)=e^{\kappa \pi(t)}
$$


As the feed-in remuneration is paid out for 20 years in Germany, this time-frame (i.e. the economic lifetime $T$ ) is taken as value for $\kappa$. The deployment $d(t)$ is modeled to be proportional to the aforementioned exponential utility function $u(t)$, with a constant $c$ to be determined by the actual uptake:

$$
d(t)=c \cdot u(t)
$$

\subsection{Prospect Utility Model}

In a seminal paper, Kahneman and Tversky introduced Prospect Theory to the scientific community (Kahneman and Tversky, 1979). Central to the theory is the idea that people often do not perceive utilities in absolute values of wealth, but rather in gains and losses relative to the current state. Moreover, as they phrase it, "losses loom larger than gains" (Kahneman and Tversky, 1979), which means that the disutility of a loss is perceived worse than the utility of a gain of the same absolute size. Prospect theory has become an integral part of behavioral economics, and has been successfully applied to problems in finance and insurance, among others (Barberis, 2013).

The theory consists of two parts; a value function which assigns values to gains and losses relative to the status quo, and a weighting function which is used to assign weights on how people perceive probabilities (people have consistently been shown to misjudge very small and very large probabilities). The value function (for a graphical depiction see figure 5 ) has a kink at the origin, meaning that relative losses cause a higher disutility (seen in the larger slope for losses compared to gains), an effect they coin with the phrase "loss aversion" (Tversky and Kahneman, 1992). Moreover, there is some "saturation" in the value curve - the slope decreases for values further away from the origin, i.e. people are more indifferent about a marginal win or loss far away from the status quo than near to it.

The theory is applied to the PV investment problem in the following way: It is postulated that potential residential PV adopters do not only rate the investment's attractiveness in absolute terms (i.e. in terms of utility derived from risk-adjusted IRR), but also in relative gains and loss, i.e. in the frame of changes of that utility function. Imagine policy makers announce to lower remunerations (the legislative plans are usually revealed several months in advance). Potential adopters realize a prospective PV system would have less profitability than as of today. In the light of loss aversion, this would be a further incentive to build in order to avoid the disutility of this potential loss, even if the absolute profitability is comparatively average.

The value function of prospect theory is parametrized as follows (Tversky and Kahneman, 1992):

$$
v(x)= \begin{cases}x^{\alpha} & \text { if } x>0 \\ -\lambda(-x)^{\alpha} & \text { if } x \leq 0\end{cases}
$$

where $x$ is a relative gain $(x>0)$ or loss $(x<0), \alpha$ is the saturation parameter and $\lambda$ the extent of the loss aversion in comparison to gains. They experimen- 


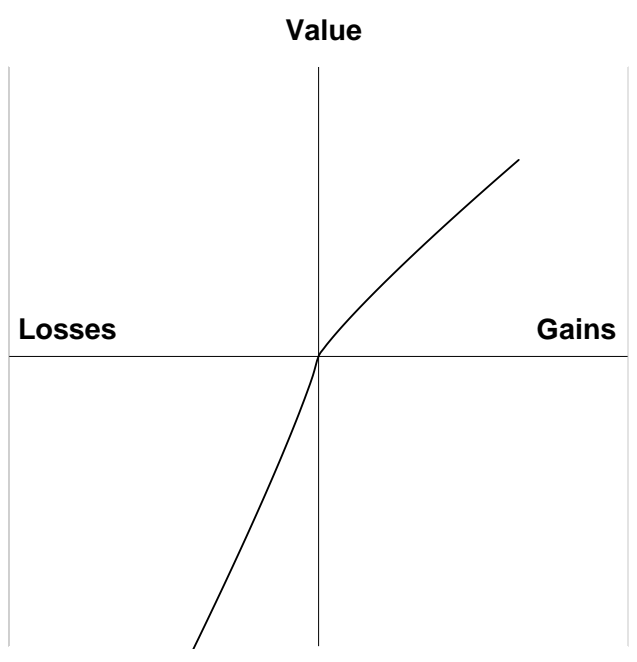

Figure 5: The value function of prospect theory. The disutility of losses is comparatively larger than the utility of gains of the same absolute size. The shape of the value function can be measured experimentally. For example, given a gambling game (like the toss of a coin) with $50 \%$ chance of losing $\$ 100$, most people start to accept the game if they have a $50 \%$ change of winning at least $\$ 200$ or more (Tversky and Kahneman, 1992) - a phenomenon far too large to be explainable by income effects (Tversky and Kahneman 1992). 
tally found $\alpha=0.88$ (i.e. only minor saturation) and $\lambda=2.25$ (i.e. losses are perceived 2.25 times as badly as gains of the same absolute extent).

This value function is used directly to model the investment dynamics. One major difficulty in applying the value function is to create a scale for gains and losses (Barberis, 2013). In our example, gains and losses are defined in terms of prospective changes in the exponential utility function $u(t)^{4}$

$$
x_{\rightarrow}(t)=u(t+\Delta t)-u(t)=e^{\kappa \pi(t+\Delta t)}-e^{\kappa \pi(t)}
$$

Additionally, one can also consider the retrospective changes in the exponential utility function:

$$
x_{\leftarrow}(t)=u(t)-u(t-\Delta t)=e^{\kappa \pi(t)}-e^{\kappa \pi(t-\Delta t)}
$$

A prospect utility function $U(t)$ of investing in $\mathrm{PV}$ is proposed, which comprises the exponential utility function $u(t)$, minus the utility of its forward change (an expected loss in the next month will increase deployment $)^{5}$ plus the utility of its backward change (a loss compared to the last month will decrease deployment):

$$
U(t)=u(t)-v\left(x_{\rightarrow}(t)\right)+v\left(x_{\leftarrow}(t)\right)
$$

with $x(t)$ from formula 15 and 16 and the value function of prospect theory $v(x)$ from formula 14 . The parametrization of the value function is left unchanged from the original source (Tversky and Kahneman, 1992 ${ }^{6}$.

The deployment per month is modeled to be proportional to the aforementioned prospect utility function $U(t)$, with a constant $k$ to be determined by the actual uptake7.

$$
d(t)= \begin{cases}k \cdot U(t) & \text { if } U(t)>0 \\ 0 & \text { else }\end{cases}
$$

\subsection{Data}

Table 2 presents an overview of the assumptions for the distributions of the Monte Carlo calculation input parameters in the study, and the respective data sources from where they are derived. By model definition, all system sizes

\footnotetext{
${ }^{4} \mathrm{~A}$ time step size $\Delta t=1$ month is used, as data resolution and feed-in tariff adjustments since 2012 have the same step size.

${ }^{5}$ Note that a prospective disutility of not investing in PV is interpreted as an incentive to build, therefore the minus sign in formula 15

${ }^{6}$ For model simplicity, conditions under certainty are assumed in the present study. Prospect theory was originally developed to assess decision under uncertainty including socalled decision weights (either very small or very large probabilities were shown to be poorly assessed by study participants) (Kahneman and Tversky 1979). However, the original authors of the theory have shown that the value function can also be applied in conditions under certainty in the same way (Tversky and Kahneman 1991).

${ }^{7}$ It is assumed that the deployment would not go to negative values if the prospect utility function went below 0 .
} 
between $>0$ and $10 \mathrm{~kW}_{\mathrm{p}}$ are equally probable, although the scaling function described in formula 3 puts a price tag on smaller systems. For model simplicity, a correlation between system size and the self-consumption ratio is not considered. The irradiance distribution is derived from openly accessible radiation maps (Huld et al., 2012). Roof inclination factors are derived from Mainzer et al. (2014). Both distributions are approximated with beta functions, which can be fully characterized by its minimum, maximum and modal value (Davis, 2008).

For the installation cost $I_{0}$ between the last quarter of 2006 and 2014 a commercial dataset is used (EuPD Research, 2016). The data describes PV system costs (turnkey ready including modules, inverter etc.) for systems $<10 \mathrm{~kW}_{\mathrm{p}}$ in 3-monthly resolution, which was linearly interpolated to get monthly values. PV deployment data is taken from sources of the Open Power System Data project (Open Power System Data, 2017), which builds on sources published by the transmission system operators and the network regulator $(50 \mathrm{Hertz}$ Transmission, 2016, Amprion, 2016, Tennet, 2016 : TransnetBW, 2016 |Bundesnetzagentur, 2016). It is assumed that all of the installations $<10 \mathrm{~kW}_{\mathrm{p}}$ were roof-top installation 8 The data contains entries for all RES installations which are incentivized via the EEG, and includes date of installation, state, capacity, and the respective distribution system operator, among others. The data was filtered for PV installations $<10 \mathrm{~kW}_{\mathrm{p}}$ to get the absolute number of monthly installations. Likely duplicates were removed before processing. No other alterations were required.

The risk-free rate is derived from the average yield on public-sector bonds, data was obtained via Deutsche Bundesbank (2016). Feed-in tariff levels were obtained from Bundesnetzagentur (2016), for an overview see SFV (2016).

Since socio-economic and environmental parameters like income and irradiance are fairly homogeneously distributed over Germany and did not change substantially over time, and data availability and the number of installations are high, the assessment of the investment dynamics is ensured to be as undistorted as possible. The analysis is restricted to the years 2006-2014: Due to data availability, the analysis starts in 2006. The years after 2014 are not considered because of the start of the adoption of PV battery systems (Kairies et al. 2015), which change the economics of PV systems considerably (Hoppmann et al. 2014). Changes in the number of available roofs were not considered, and the break condition of investigated systems of $<10 \mathrm{~kW}_{\mathrm{p}}$ is rather arbitrary; better data on both ends would reduce uncertainty regarding the actual uptake of residential photovoltaic systems. 


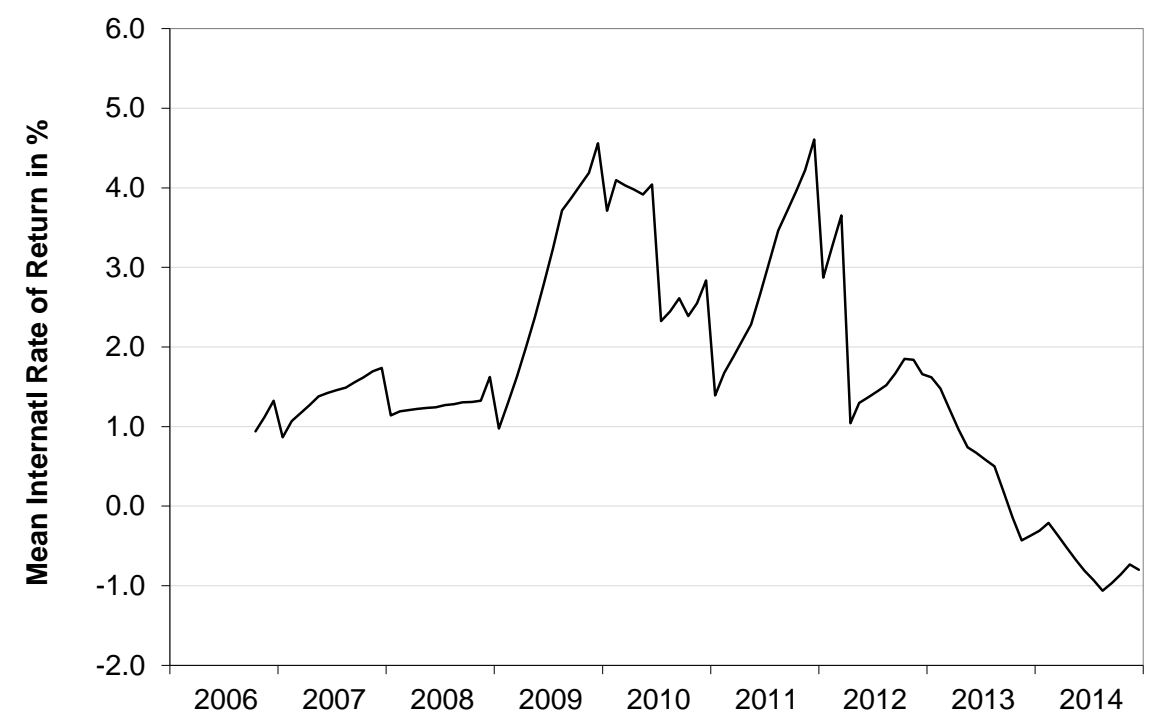

Figure 6: Calculated mean IRR of potential residential photovoltaic systems in Germany. System cost and remuneration are the fundamental determinants of profitability.

\section{Results}

Figure 6 illustrates the calculated mean IRR of possible residential photovoltaic systems over time. Since system costs and remuneration are the fundamental determinants of profitability, this graph relates to figure 1: The steps in the years 2006-2008 results from the yearly step-wise adjustment of the feed-in tariff. The profitability of PV installations rose significantly in the following years. Highest returns were possible at the end of 2009 and 2011, respectively, right before remuneration cuts. After further feed-in tariff adjustments in 2012, mean negative returns where observable (note that a mean IRR of less than $0 \%$ does not mean that there is no incentive to build at all; there might be installations well above $0 \%$, since this is only the mean value for all possible systems). The IRR alone is only moderately correlated with deployment (Pearson correlation of 0.47).

Figure 7 shows the fit of the exponential utility model $u(t)$. The overall shape of the deployment curve is covered, but the dynamics of the sub-yearly peaks of installations are insufficiently represented. A moderate Pearson correlation of 0.62 is obtained $(p<0.001)$. The scaling factor is empirically found to be $c=7845.5$ to match with the absolute deployment over the time-frame under

\footnotetext{
${ }^{8}$ This is a necessary assumption, as the installation data published by the transmission system operators is not reliably differentiated between roof-top and ground-mounted PV systems. However, ground-mounted PV systems tend to be much larger (near the $\mathrm{MW}_{\mathrm{p}}$ range), so error should be minor, although unknown in magnitude.
} 


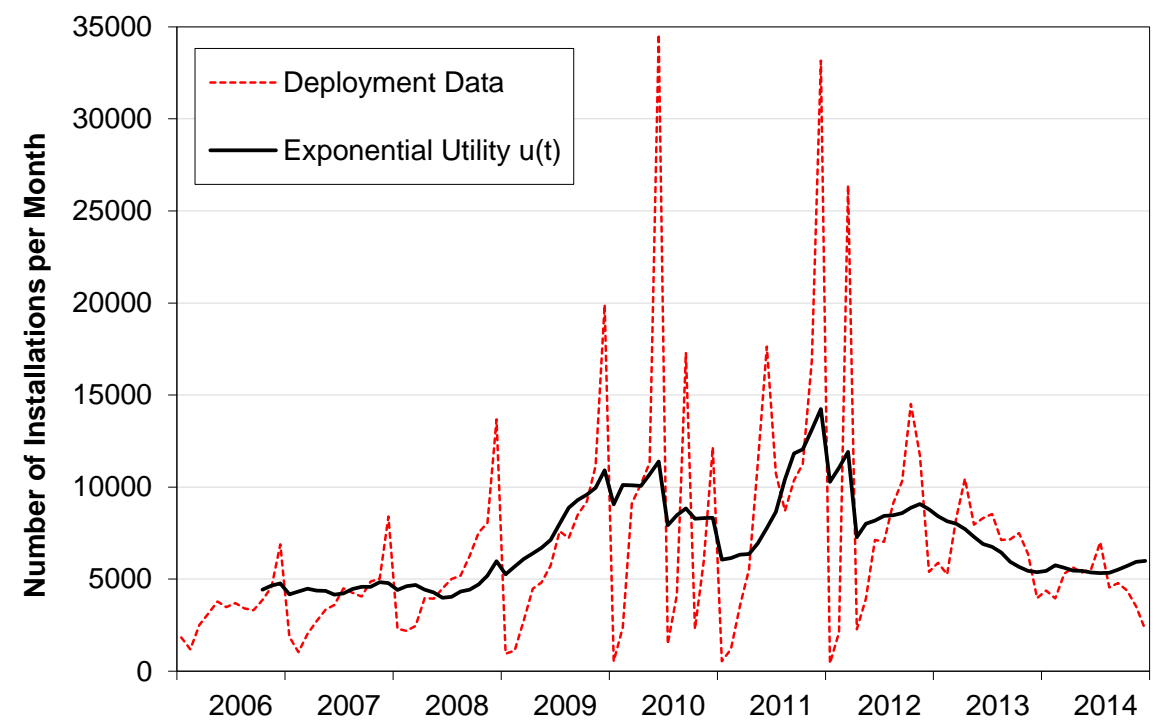

Figure 7: Data and exponential utility model results for the monthly number of PV installations. The dashed line shows the observed number of monthly installations of residential PV systems. It is superimposed with the results of the fit of the exponential utility function to the data, indicated by the solid line. The dynamics of the sub-yearly peaks of installations are insufficiently represented.

consideration.

The goodness of fit can be substantially improved if the value function of prospect theory is incorporated into the evaluation (figure 8). The overall shape of the deployment curve with its stylized features is represented well, most notably the pronounced peaks and valleys. Not all peaks are met precisely in their height. Nevertheless, the location of the peaks is almost always found. A high Pearson correlation of 0.85 is obtained $(p<0.001)$. One notable exception is the observed deployment peak in mid 2011; its probable origin will be examined in the discussion section. The scaling factor for this case is empirically found to be $k=7516.2$. Table 1 gives an overview of the fitting results.

\section{Discussion}

\subsection{Sensitivity Analysis}

Note that the results were not subject to careful parameter adjustment. Fitting is only performed in the last step of the analysis to translate the relative utility scales to absolute deployment levels. This is remarkable because the value function has been parametrized in a completely different context (lab controlled gambling games (Tversky and Kahneman, 1992)) and is applied with unchanged parametrization to this case. To study the influence of this implicit parameter choice, a sensitivity analysis of the functional parameters of the value function 


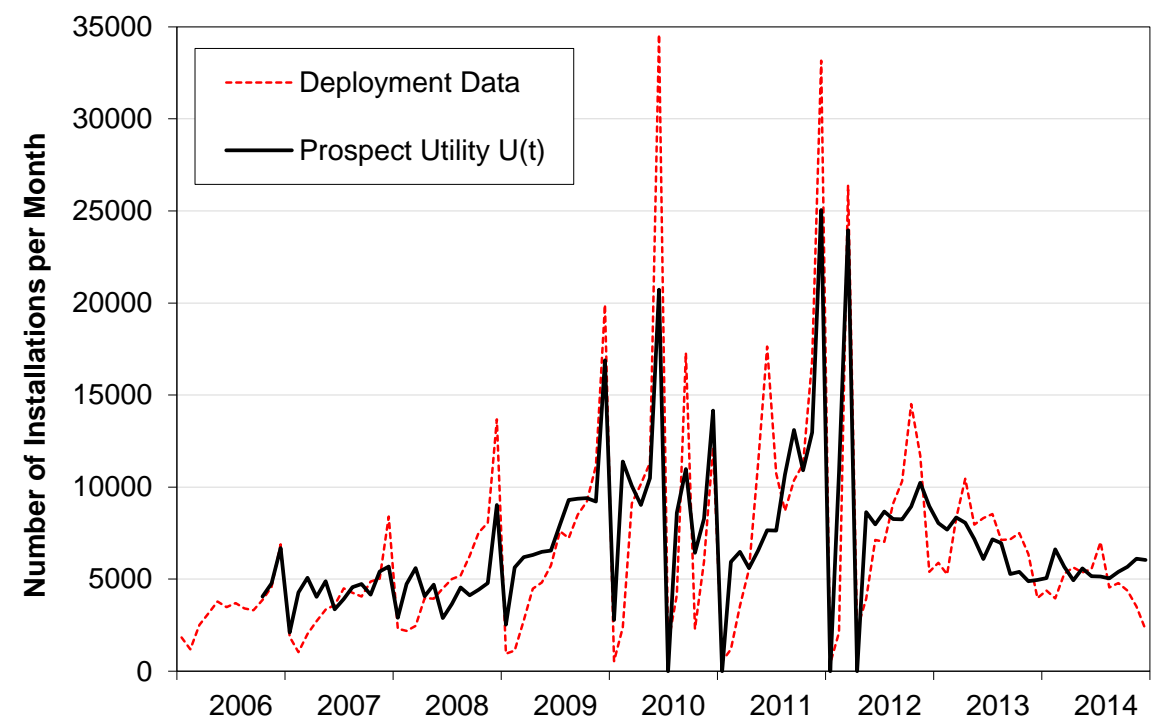

Figure 8: Data and prospect utility model results for the monthly number of $P V$ installations. The dashed line shows the observed number of monthly installations of residential PV systems. The superimposed solid line is the fit of the prospect utility function to the data, i.e. the exponential utility function combined with the value function of prospect theory. The stylized features of the deployment curve are represented substantially better.

( $\alpha$ and $\lambda$, see formula 14 is performed. The sensitivity plots are shown in figures 910

Lower numerical values for $\alpha$ correspond to a higher saturation of the value function - the magnitude of the value change becomes less relevant. Hence, smaller fluctuations in the exponential utility function $u(t)$ lead to comparatively higher deployment peaks and valleys (see for example the years 2006-2008, figure 9p. For very small values of $\alpha<0.5$, the model represents the deployment data poorly.

The extent of loss aversion is parametrized with $\lambda$. If, for example, losses are perceived twice as badly as gains of the same absolute extent, $\lambda$ would take the value of 2 . With higher levels of $\lambda$, the deployment peaks and valleys become more prominent in the uptake model (figure 10), as losses would be perceived comparatively higher. Overall, the model is rather robust towards changes in the parameter $\lambda$, the stylized features of the deployment curve are represented well for a broad window of parameters.

Additionally, a sensitivity analysis of parameter $\kappa$ of the exponential utility function (see formula 12 is performed. The plot is shown in figure 11. Higher values of $\kappa$ correspond to comparatively higher utility values for higher riskadjusted returns $\pi(t)$. Hence, with higher levels of $\kappa$, comparatively more uptake is predicted when risk-adjusted returns are higher (mostly between 2009-2012). 


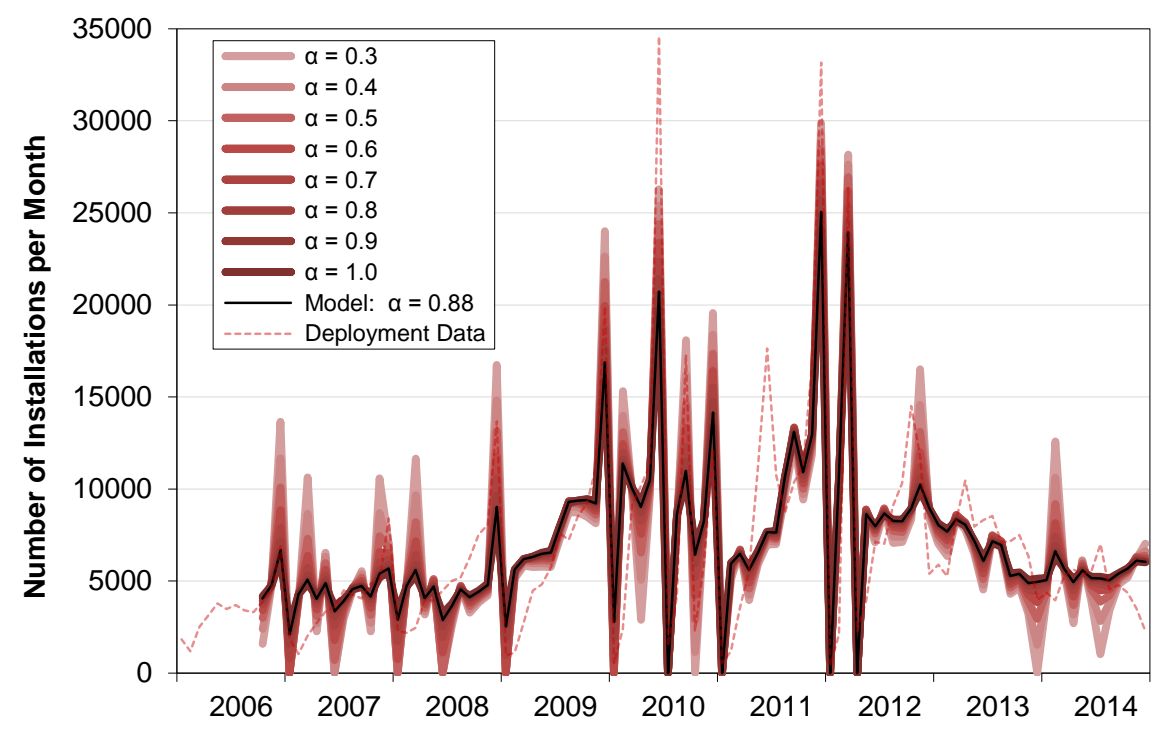

Figure 9: Sensitivity of the numerical value of $\alpha$ from the value function of prospect theory (formula 14) on the uptake model.

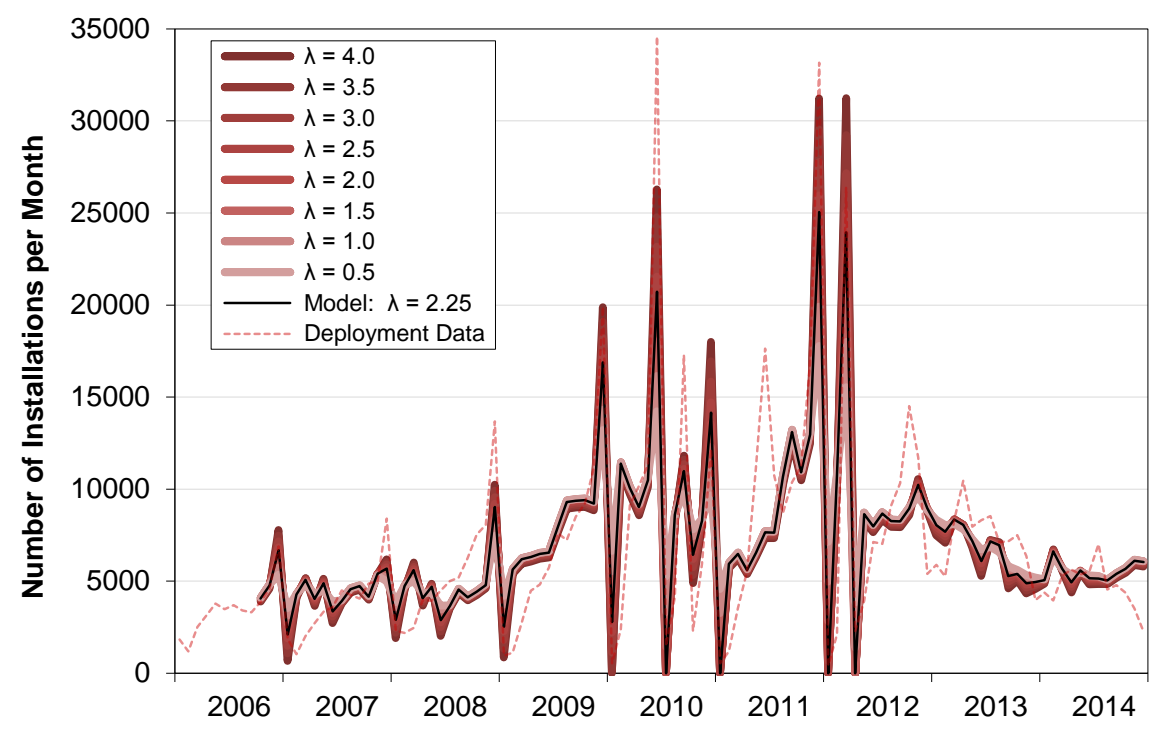

Figure 10: Sensitivity of the numerical value of $\lambda$ from the value function of prospect theory (formula 14) on the uptake model. 


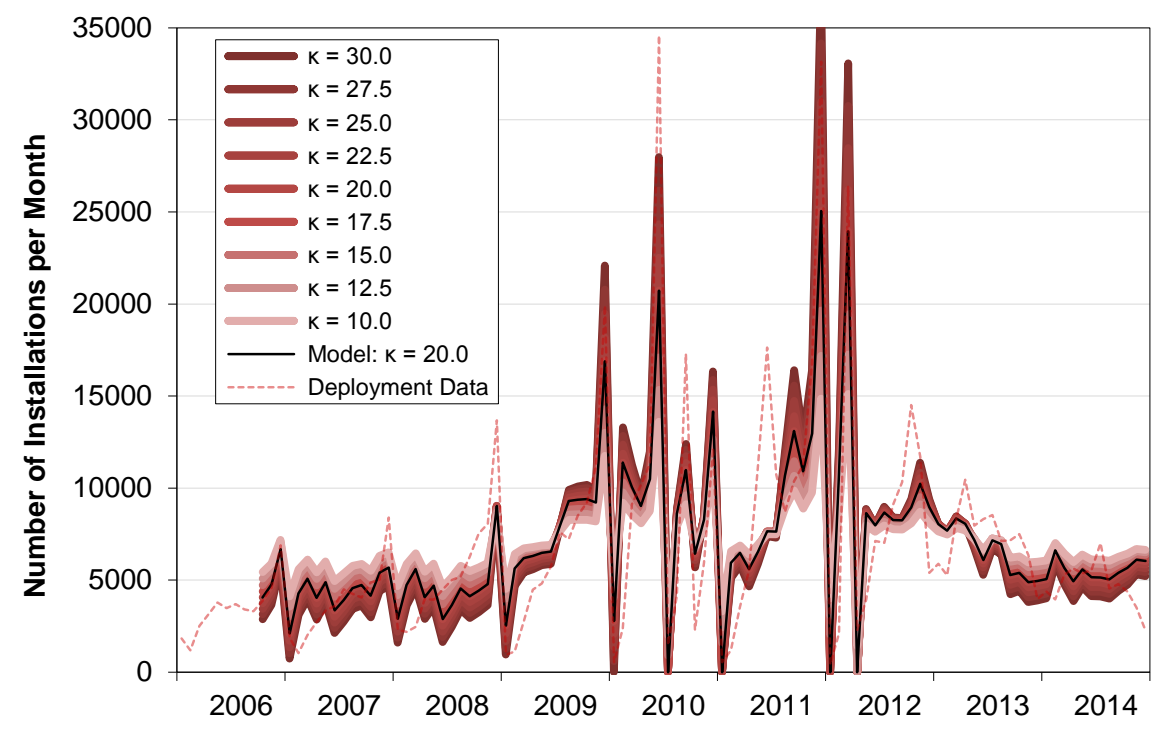

Figure 11: Sensitivity of the numerical value of $\kappa$ from the utility function (formula 12) on the uptake model.

\subsection{Interpretation of the results}

The data shows that investments increase right before a reduction of the remuneration - a policy change induces a strengthened uptake. This notion can be extracted out of the deployment curve without further numerical analysis (see figure 2). Peak deployment dynamics are represented via the frame of gains and losses of investors based on Kahneman and Tversky's value function. Together with a common net present value calculation, this seems to fill the explanation gap of the observed German PV installation data.

The sensitivity analysis reveals that the model is rather robust towards the parametrization of the value function and the exponential utility function. Therefore, the presented approach is considered "fundamental" in a sense that it can be directly derived from fundamental economic considerations (like the utility from compound interest over 20 years) or from behavioral experiments (like shape of the value function).

It is probable that most people do not account and reason about PV in the way as it has been presented in the paper (it has in fact been shown by Salm et al. (2016) and several other studies that a large share of PV adopters rely on "gut feelings" and simple heuristics like payback times). Is it therefore reasonable to focus solely on the described (behavioral) economic aspects? The proposed theoretical approach does not cover possible word of mouth effects or even personal values of investors. Though internal factors of decision makers play a role in general and may also interact and influence with external factors as Kastner and Matthies (2016) suggest, the study evaluates financial incentives 
solely. Thus, the dataset and methodology does not allow for conclusions about the effect of internal factors (like personal norms, values and attitudes) on the investment decision. However, it is likely that improved economics will convince more people to adopt, no matter if they are convinced environmentalists or if they view photovoltaics just as an attractive investment among others, as the financial attractiveness should shift the attitude concerning investment of all actor groups in the same direction. The study can therefore help to understand how the economic prospect and its changes affect the overall adoption pattern. In a sense, it is remarkable how much one can explain with economic prospects alone.

\subsection{Possible extensions of the study}

The presented method can be used for forecasting. The prospect utility model might help policy makers find appropriate remuneration levels to reach desired deployment goals. For example, the study could be used to craft exploratory energy scenarios which depict the uptake of future energy technology combinations like PV battery systems. Additionally, the study helps to understand the influence of bond rates on deployment levels - in agreement with Leepa and Unfried (2013), it could be shown that the economic assessment largely benefits if the risk-free return rates are factored in. For example, PV deployment would have been lower according to the model if interest rates had remained at above financial crisis levels. This paper, however, abstains from using the model in a forecasting or scenario fashion as the results should get validated with a different case study first.

Future work should examine and apply this method to other cases and countries or to other kinds of (institutional) investors to see if those data patterns are still observable. The proposed model should be indifferent to remuneration policy instruments, i.e. should not be limited to feed-in tariff schemes, as the NPV calculation method is by definition only subject to cash-flows, irrespective where they come from (purchasing agreements, tax credits, etc.). Furthermore, the method should be applicable to any kind of energy investments, if the investment in question is not mutually exclusive but to the standard risk-less choice of bonds, and has short installation times and low running cost. This means on the contrary that other energy technologies with long project development times like wind power will be harder to depict as the time gap between investment decision and implementation will be higher.

Furthermore, one could investigate socio-economic or spatial aspects of the described effect. Possible investors might become aware of remuneration schemes via word of mouth effects or media representation of the topic. The authors cannot estimate the influence of peer to peer effects with the given data; investigating the impact of these effects on the investment dynamics would require a different research design in order to compellingly work out possible correlation patterns. However, some aggregated information about the overall "likelihood" of investment irrespective of financial concerns is contained in the scaling factor $k$, which is determined as a final step to link the prospect utility measure and the absolute observed deployment (see formula 18). The value $k$ determines 
how much uptake is obtained given ceteris paribus economic conditions; it can potentially change over time if the attitude towards the technology changes. One of the installation peaks can be an indication of this happening: The installation peak in mid 2011 is not covered by the prospect utility model. This peak coincides with the Fukushima disaster and a public attitude shift towards renewable energy in Germany. Future studies could look into temporal and spatial aspects of the fitting value $k$.

There might be a fundamental explanation other than "irrational" loss aversion for the pronounced peak structure: Option value. The option value framework considers uncertainty as a main factor influencing investment decisions. The larger the uncertainties, e.g. development of electricity prices or changing policy incentives, the less likely the investment. Thus households would delay a favorable investment in order to "buy time" and to wait until uncertainty is resolved or better investment opportunities arise (Bauner and Crago, 2015). In the context of the option value framework, an expected decrease of remuneration of electricity from PV could lead to an increased uncertainty of future profits, as they depend more and more on volatile market prices. This might raise investments before a change of remuneration. Vice versa, an expected increase of remuneration could delay investments. So option value can also describe the effect of policy changes on the uptake of household PV investments.

The option value framework however considers rational decision making based on uncertainties and thus differs significantly from the proposed description based on the boundly rational perception of anticipated losses (which is substantially more myopic as only changes of utility one month in advance are considered). Further studies could look into the differences of both approaches in a more structured way to get deeper insights into their pros and cons and to which extent real world residential energy decisions are rationally grounded.

\section{Conclusions and Policy Implications}

The presented paper offers a new perspective on the residential PV investment dynamics in Germany and successfully combines a NPV analysis with prospect theory. Although the decision whether and when to invest in photovoltaic systems is influenced by many factors, the selected approach could reproduce most of the dynamics of the uptake with only a few financial and behavioral assumptions. There are only few widely accepted applications of prospect theory in economics (Barberis, 2013) - the proposed model is one of the first numerical applications in the energy sciences to the authors' knowledge. The proposed approach requires only one fitting parameter and is thus fundamental and parsimonious enough to be incorporated into whole system energy studies.

The study is useful for policymakers in several ways. A better understanding of the impact of deployment policies can help to design more robust remuneration schemes. By and large, the observed deployment of residential photovoltaics in Germany can be explained by the anticipation of profitability, and most notably, additionally by its anticipated change. 
Stepwise changes in the remuneration design can therefore induce non-linear and non-intended investment behavior. According to the model, this effect is temporary however, and poses only a problem if a narrow window of uptake is considered when re-adjusting the height of remunerations over time.

\section{Acknowledgments}

We would like to thank Ulrich Frey, Kristina Nienhaus, Matthias Reeg, André Thess and Laurens de Vries for fruitful discussions about this work. We also benefited from comments by members of the Helmholtz Research School on Energy Scenarios, the ETH Zürich PhD Academy on Sustainability and Technology in Appenzell (Switzerland) in 2015, the 14th Symposium Energy Innovation in Graz (Austria) and the 5th BAEE Research Workshop on Energy Economics in Delft (The Netherlands) in 2016. Dominique Heiken provided valuable research assistance. We thank François Lafond for providing data on PV module costs. The study was financed by the basic funding of DLR, which we kindly acknowledge. The authors declare no competing financial interests. 


\section{References}

50Hertz Transmission, 2016. EEG-Anlagenstammdaten.

URL http://www.50hertz.com/de/EEG/Veroeffentlichung-EEG-Daten/ EEG-Anlagenstammdaten

Allcott, H., Mullainathan, S., Mar 2010. Behavior and energy policy. Science 327 (5970), 1204-1205.

URL http://dx.doi.org/10.1126/science.1180775

Amprion, 2016. Latest EEG plant master data.

URL http://www.amprion.net/en/latest-eeg-plant-master-data

Barberis, N. C., Feb 2013. Thirty years of prospect theory in economics: A review and assessment. Journal of Economic Perspectives 27 (1), 173 - 196. URL http://dx.doi.org/10.1257/jep.27.1.173

Bauner, C., Crago, C. L., Nov 2015. Adoption of residential solar power under uncertainty: Implications for renewable energy incentives. Energy Policy 86, $27-35$.

URL http://dx.doi.org/10.1016/j.enpol.2015.06.009

BDEW, 2016. BDEW-Strompreisanalyse November 2016.

URL https://www.bdew.de/internet.nsf/res/ 17C4483BB515C7F4C125807A0035E077/\$file/161124_BDEW_

Strompreisanalyse_November2016.pdf

Bollinger, B., Gillingham, K., Nov 2012. Peer effects in the diffusion of solar photovoltaic panels. Marketing Science 31 (6), $900-912$.

URL http://dx.doi.org/10.1287/mksc.1120.0727

Brealey, R. A., Myers, S. C., 2000. Priciples of Corporate Finance, 6th Edition. McGraw-Hill.

Bundesnetzagentur, 2016. Archivierte Datenmeldungen.

URL https://wWw. bundesnetzagentur.de/cln_1412/DE/ Sachgebiete/ElektrizitaetundGas/Unternehmen_Institutionen/ ErneuerbareEnergien/Photovoltaik/ArchivDatenMeldgn/ ArchivDatenMeldgn_node.html

Candelise, C., Winskel, M., Gross, R. J., Oct 2013. The dynamics of solar PV costs and prices as a challenge for technology forecasting. Renewable and Sustainable Energy Reviews 26, 96 - 107.

URL http://dx.doi.org/10.1016/j.rser.2013.05.012

Chronopoulos, M., Hagspiel, V., Fleten, S.-E., 2016. Stepwise green investment under policy uncertainty. The Energy Journal 37 (4), 87 - 108.

URL hhtp://dx.doi .org/10.5547/01956574.37.4.mchr 
Darling, S. B., You, F., Veselka, T., Velosa, A., 2011. Assumptions and the levelized cost of energy for photovoltaics. Energy Environ. Sci. 4 (9), 3133. URL http://dx.doi.org/10.1039/c0ee00698j

Davis, R., May 2008. Teaching note - Teaching project simulation in excel using PERT- beta distributions. INFORMS Transactions on Education 8 (3), 139 -148 .

URL http://dx.doi.org/10.1287/ited.1080.0013

Deutsche Bundesbank, 2016. Macro-economic time series detail view values. URL https://www.bundesbank.de/Navigation/EN/Statistics/Time_ series_databases/Macro_economic_time_series/its_details_value_ node.html?https=1\&tsId=BBK01. WT0115

EuPD Research, 2016. Photovoltaik-Preismonitor Deutschland, Ergebnisse 4. Quartal. Tech. rep., Bundesverband Solarwirtschaft e.V. (BSW-Solar).

Farmer, J. D., Lafond, F., Apr 2016. How predictable is technological progress? Research Policy 45 (3), 647-665.

URL http://dx.doi.org/10.1016/j.respol.2015.11.001

Feldman, D., Barbose, G., Margolis, R., Wiser, R., Darghouth, N., Goodrich, A., 2012. Photovoltaic (PV) pricing trends: Historical, recent, and near-term projections. Tech. Rep. DOE/GO-102012-3839, National Renewable Energy Laboratory, Lawrence Berkeley National Laboratory. URL http://www.nrel.gov/docs/fy13osti/56776.pdf

Grau, T., Jul 2014. Responsive feed-in tariff adjustment to dynamic technology development. Energy Economics 44, $36-46$. URL http://dx.doi.org/10.1016/j.eneco.2014.03.015

Hacura, A., Jadamus Hacura, M., Kocot, A., Apr 2001. Risk analysis in investment appraisal based on the Monte Carlo simulation technique. The European Physical Journal B 20 (4), $551-553$.

URL http://dx.doi.org/10.1007/s100510170238

Hillier, F. S., Apr 1963. The derivation of probabilistic information for the evaluation of risky investments. Management Science 9 (3), $443-457$. URL http://dx.doi.org/10.1287/mnsc.9.3.443

Hoppmann, J., Peters, M., Schneider, M., Hoffmann, V. H., May 2013. The two faces of market support - How deployment policies affect technological exploration and exploitation in the solar photovoltaic industry. Research Policy $42(4), 989-1003$.

URL http://dx.doi.org/10.1016/j.respol.2013.01.002

Hoppmann, J., Volland, J., Schmidt, T. S., Hoffmann, V. H., Nov 2014. The economic viability of battery storage for residential solar photovoltaic systems 
- A review and a simulation model. Renewable and Sustainable Energy Reviews $39,1101-1118$.

URL http://dx.doi.org/10.1016/j.rser.2014.07.068

Huld, T., Müller, R., Gambardella, A., Jun 2012. A new solar radiation database for estimating PV performance in Europe and Africa. Solar Energy 86 (6), $1803-1815$.

URL http://dx.doi.org/10.1016/j.solener.2012.03.006

Jordan, D. C., Kurtz, S. R., Oct 2011. Photovoltaic degradation rates - An analytical review. Progress in Photovoltaics: Research and Applications 21 (1), $12-29$.

URL http://dx.doi.org/10.1002/pip.1182

Kahneman, D., Tversky, A., Mar 1979. Prospect theory: An analysis of decision under risk. Econometrica 47 (2), 263-292.

URL http://dx.doi .org/10.2307/1914185

Kairies, K.-P., Magnor, D., Sauer, D. U., Jun 2015. Scientific measuring and evaluation program for photovoltaic battery systems (WMEP PV-Speicher). Energy Procedia 73, $200-207$.

URL http://dx.doi .org/10.1016/j .egypro.2015.07.672

Kastner, I., Matthies, E., Jul 2016. Investments in renewable energies by German households: A matter of economics, social influences and ecological concern? Energy Research \& Social Science 17, 1 - 9.

URL http://dx.doi.org/10.1016/j.erss.2016.03.006

Korcaj, L., Hahnel, U. J., Spada, H., Mar 2015. Intentions to adopt photovoltaic systems depend on homeowners' expected personal gains and behavior of peers. Renewable Energy 75, 407-415.

URL http://dx.doi.org/10.1016/j.renene.2014.10.007

Kwan, C. L., Aug 2012. Influence of local environmental, social, economic and political variables on the spatial distribution of residential solar PV arrays across the United States. Energy Policy 47, 332-344.

URL http://dx.doi.org/10.1016/j.enpol.2012.04.074

Leepa, C., Unfried, M., May 2013. Effects of a cut-off in feed-in tariffs on photovoltaic capacity: Evidence from Germany. Energy Policy 56, 536 - 542.

URL http://dx.doi .org/10.1016/j .enpol.2013.01.018

Lobel, R., Perakis, G., January 26 2011. Consumer choice model for forecasting demand and designing incentives for solar technology, working paper.

URL http://dx.doi.org/10.2139/ssrn.1748424

Luthander, R., Widén, J., Munkhammar, J., Lingfors, D., Oct 2016. Selfconsumption enhancement and peak shaving of residential photovoltaics using storage and curtailment. Energy 112, 221-231.

URL http://dx.doi.org/10.1016/j.energy .2016.06.039 
Luthander, R., Widén, J., Nilsson, D., Palm, J., Mar 2015. Photovoltaic selfconsumption in buildings: A review. Applied Energy 142, $80-94$.

URL http://dx.doi.org/10.1016/j.apenergy .2014.12.028

Mainzer, K., Fath, K., McKenna, R., Stengel, J., Fichtner, W., Schultmann, F., Jul 2014. A high-resolution determination of the technical potential for residential-roof-mounted photovoltaic systems in Germany. Solar Energy 105, $715-731$.

URL http://dx.doi.org/10.1016/j.solener.2014.04.015

Open Power System Data, 2017. Data Package Renewable power plants, version 2017-02-16.

URL http://data.open-power-system-data.org/renewable_power_ plants/

Palmer, J., Sorda, G., Madlener, R., Oct 2015. Modeling the diffusion of residential photovoltaic systems in Italy: An agent-based simulation. Technological Forecasting and Social Change 99, $106-131$.

URL http://dx.doi.org/10.1016/j.techfore.2015.06.011

Rai, V., Robinson, S. A., Mar 2013. Effective information channels for reducing costs of environmentally- friendly technologies: Evidence from residential PV markets. Environmental Research Letters 8 (1), 014044.

URL http://dx.doi.org/10.1088/1748-9326/8/1/014044

Rai, V., Robinson, S. A., Aug 2015. Agent-based modeling of energy technology adoption: Empirical integration of social, behavioral, economic, and environmental factors. Environmental Modelling \& Software 70, 163 - 177.

URL http://dx.doi.org/10.1016/j. envsoft.2015.04.014

Reich, N. H., Mueller, B., Armbruster, A., van Sark, W. G. J. H. M., Kiefer, K., Reise, C., Jan 2012. Performance ratio revisited: is PR > 9020 (6), 717 726.

URL http://dx.doi.org/10.1002/pip.1219

REN21, 2016. Renewables 2016 global status report. REN21 Secretariat, Paris. URL http://www.ren21.net/GSR-2016-Report-Full-report-EN

Rode, J., Weber, A., Jul 2016. Does localized imitation drive technology adoption? A case study on rooftop photovoltaic systems in Germany. Journal of Environmental Economics and Management 78, 38-48.

URL http://dx . doi .org/10.1016/j . jeem.2016.02.001

Salm, S., Hille, S. L., Wüstenhagen, R., Oct 2016. What are retail investors' riskreturn preferences towards renewable energy projects? A choice experiment in Germany. Energy Policy 97, 310-320.

URL http://dx.doi.org/10.1016/j.enpol.2016.07.042 
Seel, J., Barbose, G. L., Wiser, R. H., Jun 2014. An analysis of residential PV system price differences between the United States and Germany. Energy Policy 69, $216-226$.

URL http://dx.doi.org/10.1016/j.enpol.2014.02.022

SFV, 2016. Solarstrom-Vergütungen im Überblick. URL http://www.sfv.de/lokal/mails/sj/verguetu.htm

Tennet, 2016. Master and movement data in TenneT's control area. URL http://www.tennet.eu/electricity-market/ german-market/eeg-kwkg/renewable-energy-source-act-eeg/ assets-reports-balancing/

TransnetBW, 2016. Annual statement of accounts pursuant to EEG.

URL https://www.transnetbw.com/en/res-kwk-g/res/ annual-statement-of-accounts

Tversky, A., Kahneman, D., 1991. Loss aversion in riskless choice: A referencedependent model. The Quarterly Journal of Economics 4 (106), 1039.

URL http://dx.doi.org/10.2307/2937956

Tversky, A., Kahneman, D., 1992. Advances in prospect theory: Cumulative representation of uncertainty. Journal of Risk and Uncertainty 5 (4), 297323.

URL http://dx.doi.org/10.1007/BF00122574

van Benthem, A., Gillingham, K., Sweeney, J., 2008. Learning-by-doing and the optimal solar policy in California. The Energy Journal 29 (3), 131 - 151.

URL http://www.jstor.org/stable/41323173

Wand, R., Leuthold, F., Dec 2011. Feed-in tariffs for photovoltaics: Learning by doing in Germany? Applied Energy 88 (12), 4387 - 4399.

URL http://dx.doi.org/10.1016/j.apenergy.2011.05.015

Zhang, M., Zhou, D., Zhou, P., Liu, G., Oct 2016. Optimal feed-in tariff for solar photovoltaic power generation in China: A real options analysis. Energy Policy 97, 181-192.

URL http://dx.doi.org/10.1016/j.enpol.2016.07.028 
Table 1: Pearson correlation coefficients for different features related to monthly deployment.

\begin{tabular}{|c|c|}
\hline Features & Pearson Correlation \\
\hline \hline Mean IRR - Monthly Deployment & 0.47 \\
\hline Mean Risk Adjusted IRR - Monthly Deployment & 0.57 \\
\hline Exponential Utility Model - Monthly Deployment & 0.62 \\
\hline Prospect Utility Model - Monthly Deployment & 0.85 \\
\hline
\end{tabular}




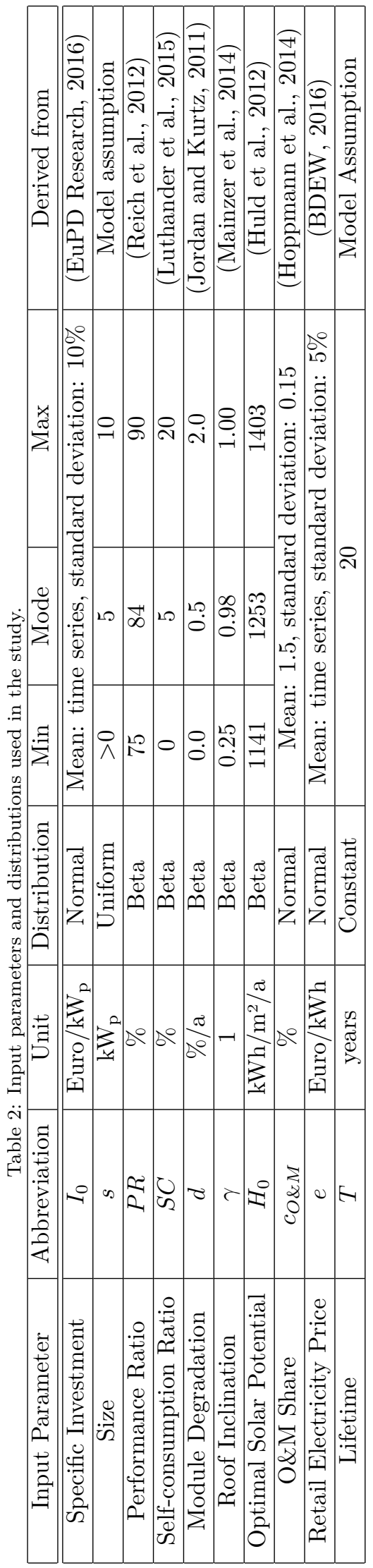

